Sweden, ${ }^{10}$ Finland, ${ }^{11}$ and Japan. ${ }^{12}$ Moreover, a decrease in the frequency of calculi commonly associated with infection by organisms that split urea has been noted in Finland ${ }^{11}$ and Boston $^{14}$ and has been attributed to the use of antibiotics. Uric-acid stones appear to be on the increase in Texas, ${ }^{15}$ Sweden, and Denmark, ${ }^{16}$ but the opposite trend has been seen in Finland. ${ }^{11}$

Remarkably little is known about the geographical distribution of stone in the urinary tract in the British Isles to-day. There are several reasons for this. It is largely a disease of young adults, and though the recurrence rate is high ${ }^{17}$ the disease is frequently self-limiting and mortality statistics do not therefore reflect the actual morbidity. A short paper by G. S. Anderson ${ }^{18}$ from Stornoway is one of the few recent attempts to establish the true incidence of urinary-tract calculus in a closed community. His main finding is that the annual hospital-admission rate for stone in the outer Hebrides was 69 patients per 100,000 population in the years 1957 to 1961. In the absence of figures from other parts of Britain, this report can be compared only with the available reports in Europe and the U.S.A. The highest incidence reported so far appears to be 193 per 100,000 in South Carolina, ${ }^{19}$ and the lowest 19 per 100,000 in Sweden. ${ }^{10}$ Thus Anderson's figures fall between the two extremes and it would be interesting to know whether they are representative of the British Isles as a whole.

An alternative and simpler approach to the problem of the incidence of stone is to record the frequency with which they are found in the urinary tract at necropsy. This has been, done by E. F. Reaser ${ }^{20}$ in Washington, who found calculi in $1.3 \%$ of 5,900 necropsies, and by E. T. Bell ${ }^{21}$ in Philadelphiar who found them in $1.1 \%$ of 24,561 . Owing to the age incidence of renal-stone disease these figures must underestimate the actual morbidity in the population, but they are sufficiently similar to suggest that there is no striking difference in stone incidence between these two cities. A similar study in Britain $^{22}$ yielded a figure of $0.18 \%$ of 26,832 necropsies, but this is not strictly comparable to the American figures because cases diagnosed in life were excluded from the series.

\section{Congenital Laryngeal Stridor}

The term "benign congenital laryngeal stridor" denotes a condition in which a child has an inspiratory stridor from birth, worse on crying, associated with indrawing of the chest, and usually undergoing cure by the age of 12 to 18 months. It is commonly ascribed to lax or superfluous arytenoepiglottideal folds.

Unfortunately diagnosis is not always easy. It is commonly held that congenital stridor which is purely inspiratory is benign, while a stridor which is both inspiratory and expiratory is liable to be much more serious, possible causes of the latter being a web between the vocal cords, a poiyp or papilloma of the cords, an angioma below the cords, tracheomalacia, or a vascular ring within the thorax. Few people now believe that an enlarged thymus is a cause of stridor.

Some ten years ago James Crooks ${ }^{1}$ described examples of inspiratory stridor due to other causes. All were amenable to surgical treatment and all were potentially fatal. Four of these infants had a cyst-two of them in the aryepiglettic fold, one on the back of the tongue, and one derived from the ventricle of the larynx. Two had a subglottic haemangioma, one had a cleft larynx, and one had a foreign body. He regarded $90 \%$ of cases as being due to an exaggerated pattern of the infantile larynx, recovering within a year or so, but $10 \%$ as being due to other causes. $\mathrm{He}$ advised investigation of all cases.

P. H. Holinger and K. C. Johnston ${ }^{2}$ reached a similar conclusion. In a comprehensive review of the condition they wrote that the inspiratory stridor is usually but not always benign, and that a subglottic haemangioma usually caused a purely inspiratory stridor. They emphasized the importance of a change in voice-namely, hoarseness-whether associated with a purely inspiratory stridor or otherwise, as pointing to a more serious condition such as a laryngeal web or paralysis of a recurrent laryngeal nerve. Feeding difficulties were often found to be associated with the so-called benign congenital laryngeal stridor. These authors considered that all infants with stridor, even though it is purely inspiratory, should be investigated.

Clearly it is not safe to assume that a purely inspiratory stridor is necessarily benign, even when it is due to lax aryteno-epiglottideal folds. Some paediatricians have thought, like Holinger and Johnston, that feeding difficulties such as regurgitation and choking on feeding are more common in affected infants than in others. Cyanotic attacks, not necessarily associated with feeds, are rather common and are very alarming, especially to the parents.

In a review of 78 cases of inspiratory stridor J. Apley, ${ }^{3}$ of Bristol, reported that nine out of ten infants had lost the symptom within two years, but he found micrognathia in five of his patients, congenital heart disease in six, and polydactyly in one. There were three mongols, and 16 other children were mentally retarded, two being spastic. Two had a meningomyelocele. Half had feeding difficulties. There was frequently an association with snuffles and with excessively frequent lung infections. Three had a vascular ring in the thorax. The birth weight tended to be higher than average. Eleven died. He thought that in some of the cases the lesion was in the central nervous system, not in the throat. Certainly inspiratory stridor sometimes affects infants with hydrocephalus in whom no local laryngeal or supralaryngeal lesion can be found.

The high incidence of mental subnormality in Apley's study is disturbing. It must be borne in mind that an infant with any major congenital anomaly is somewhat more likely than other infants to have mental subnormality, and it may be that those infants who had an inspiratory stridor and who proved to have mental subnormality had other congenital anomalies. The need for further investigation was indicated by Apley's work.

Now R. C. Benians and his colleagues ${ }^{4}$ at Guy's Hospital have described how they followed up 21 children with congenital laryngeal stridor in order to assess their neurological and mental status. The diagnostic criteria seemed to be reasonably satisfactory, and the authors considered that there was no bias in the selection of their cases except that they tended to be the more severe ones. The age at followup examination varied from 6 months to 11 years, 19 of

\footnotetext{
Crooks, J., Arch. Dis. Childh., 1954, 29, 12. Holinger, P. H., and Johnston, K. C., Pediat. Clin. N. Amer., 1955, 2,

s Apley, J., Arch. Dis. Childh., 1953, 28, 423. 'Benians, R. C., Benson, P. F., Sherwood, T., and Spector, R. G.,
Guy's Hosp. Rep., 1964, 113, 360.
} 
the patients being over 2 years of age. Only 13 were free from neurological sequelae. Two had died, two had cerebral diplegia with severely subnormal intelligence, two had hypotonic cerebral palsy (one with severely subnormal intelligence and one with low average intelligence). Another was mentally subnormal with fits, and another had a low average intelligence with fits. Generalized convulsions had occurred in five of the 21 children. The authors concluded there was a high incidence of intellectual and neurological impairment in these patients, and thought that cerebral anoxia was the cause in some but not all cases. This work is important, and confirmation or otherwise should be obtained by studies of similar cases elsewhere. If it is confirmed, it is clear that the adjective "benign" should be omitted from the condition called "benign congenital laryngeal stridor."

\section{Impressions of Health Centres}

Few other topics of medical organization can have commanded so much unanimity of support from widely differing bodies, but for differing reasons, as the concept of the health centre. Yet comparatively little has been done. The Dawson report, ${ }^{1}$ which fathered the idea, is now 45 years old, and 17 years have passed since the National Health Service, of which health centres were envisaged as a cornerstone, was introduced. 1948 was also the year in which the L.C.S. proposed ultimately to divide the county of London into 162 health service areas, each with its comprehensive health centre. ${ }^{2}$

The Dawson report, on which The Times commented, "By adding at once to the working power of the general practitioner they [health centres] must serve to relieve the strain on all hospitals, and this perhaps to an extent not yet realized," proposed that general practitioners should be based on primary health centres, which would have facilities for laboratory and radiological investigations, together with generalpractitioner beds. Those who see these as being among the urgent needs of general practice to-day will recognize the farsightedness of Lord Dawson and his Committee. An interim report ${ }^{4}$ by the Council of the B.M.A. on health centres in 1948 concluded that the most serious defects of practice organization were the arbitrary fragmentation of family doctoring into preventive and therapeutic work, the isolation of many doctors, the lack of ancillary help, and the waste of the doctor's time resulting from poor conditions of work-defects which figure prominently in current medico-political debate. To correct them Council suggested that the logical future development should be specially designed health centres, not imposed on the profession but built after local consultation. The most urgent need, the report continued, was for actual experiment with various

1 An Interim Report to the Minister of Health by the Consultative Council on Medical and Allied Services, 1920. H.M. Stationery Office, London.

2 Brit. med. F., 1948. 1, 988.

s The Times, 28 May, 1920, p.13.

- Brit. med. F. Supplement, 1947, 2, 107

s Ibid., Supplement, 1951, 2, 105.

- Ibid., Supplement, 1956, 2, 89.

' Sluglett, J., Health Centre Report, 1960. Medical Practitioners Union, London.

- The Case for Health Centres, by a General Practitioner, 1964. Socialist Medical Association, Lcndon. types of centres-a plea that was echoed in the final report three years later, in 1951. In 1956 the London Local Medical Committee ${ }^{6}$ claimed that there was an urgent need for health centres of modest proportions where both curative and preventive services would be provided. Commenting on Dr. Joseph Sluglett's commissioned report ${ }^{7}$-the most comprehensive survey of British centres to appearthe Council of the M.P.U. ${ }^{7}$ said that, though health centres must ultimately be the basis of a fully developed health service, there was a case for a new concept mid-way between group practice and health centres. These "medical centres" might be built by a trust financed by the Minister of Health, and should be owned jointly by the public and the doctors. Family doctors, they thought, should practise exclusively from these centres and undertake maternity and child-welfare clinics, while they should have a subsidized rental, complete security of tenure, and auxiliary help. The Socialist Medical Association ${ }^{8}$ has also stated that there is a " need for that promise [health centres in the N.H.S. Act, 1946] to be kept, and the time is ripe, as never before, for its implementation."

Clearly health centres would not solve the present problems of family doctors overnight, but more doctors seem to be agreeing that the proper practice of modern medicine in general practice requires the facilities that can be provided only in some sort of medical centre. What sort of centres these should be and how they should be adapted to local needs is a matter for further debate. The outcome will closely affect the future of general-practitioner medicine. At p. 1429 of this week's B.M.F. we publish the first of a short series of impressions of existing health centres and diagnostic units by a special correspondent. They will describe what has already been done in various areas, whether urban or rural, and mention some plans in progress

\section{Annual Meeting}

Many subjects of first importance in clinical practice are to be considered at the Annual Meeting of the B.M.A. in July at Swansea. Experts are to make their contributions, for instance, to discussing current ideas on bronchitis, duodenal ulcer, backache, and menorrhagia. And the somewhat neglected problem of alcoholism is to be the subject of a panel discussion. General themes to be debated concern world population (chairman Sir Julian Huxley) and the routine medical check-up (chairman Lord Hill of Luton). In addition a variety of more specialized topics are also to be lectured on, while two clinicopathological conferences, a variety of medical films, and visits to industrial works of special interest are also planned.

The full programme appears in the Supplement this week at page 211, and, as well as the serious fare, it offers a variety of diversions and entertainments. Owing to its proximity to bold coastal scenery and to delightful country inland, Swansea can provide unusually pleasant trips by boat and coach to places of interest. A very warm welcome awaits doctors and their wives, but as usual early booking of accommodation is essential, for only a limited amount is still available. Further information on that is given in the programme, where details will also be found of concessional fares for railway travellers. 